\title{
APLIKASI LAYANAN INFORMASI ABSEN DAN NILAI BERBASIS SMS GAYEWAY MENGGUNAKAN PHP PADA SMK TARUNA PERSADA DUMAI
}

\author{
M. Ilham Sugiarto ${ }^{1}$, Arie Linarta ${ }^{2}$, Amat Sofiyan $^{3}$ \\ ${ }^{1,2,3}$ Sekolah Tinggi Manajemen Informatika dan Komputer (STMIK) Dumai \\ Jalan Bukit Batrem Kota Dumai kode pos 28811 \\ e-mail : outsiderilham@gmail.com
}

\begin{abstract}
ABSTRAK
Pengelolaan informasi data Absen dan Nilai Di SMK Taruna Persada Dumai masih menggunakan Microsoft excel dan word yang membutuhkan waktu yang lama, Selain itu masih belum adanya sistem khusus informasi dari pihak sekolah kepada orang tua atau wali siswa mengenai informasi absen dan nilai siswa. Dengan demikian dirancanglah sebuah aplikasi informasi absen dan nilai berbasis SMS Gateway untuk mengirimkan informasi berupa dalam bentuk sms dan menyediakan informasi kepada orang tua atau wali siswa mengenai informasi Absen dan Nilai berbasis SMS Gateway. Dengan adanya aplikasi layanan informasi absen dan nilai berbasis SMS Gateway ini sistem bisa memberikan informasi berupa absen dan nilai siswa kepada para orangtua melalui sms yang diharapkan dapat mengatasi masalah yang ada pada sekolah ini.
\end{abstract}

Kata kunci : SMS Gateway, PHP, MySQL, Absen, Nilai.

\section{PENDAHULUAN}

SMK Taruna Persada Dumai merupakan salah satu lembaga pendidikan formal yang berkembang di kota Dumai. Bertujuan mempersiapkan tamatan untuk memasuki lapangan kerja serta mengembangkan karir sesuai dengan bidang keahlian. Salah satu faktor yang penting dalam sekolah adalah absensi dan nilai. Permasalahan yang dialami sekolah ini adalah tidak adanya sistem yang dapat memberikan informasi yang cepat mengenai absen dan nilai siswa. Sering terjadinya siswa yang sengaja tidak hadir / bolos tanpa sepengetahuan orangtua pada saat jam sekolah dan penyelewengan nilai asli yang tidak tersampaikan tanpa sepengetahuan orangtua dapat menjadi masalah yang besar jika tidak diatasi. Untuk itu dibutuhkan suatu sistem yang dapat mengatasi masalah tersebut yaitu dengan dirancangnya suatu sistem SMS Gateway. SMS Gateway adalah suatu aplikasi yang memungkinkan kita untuk menerima atau mengirim sms, sebagai pengganti perangkat telekomunikasi (handphone, modem). SMS Gateway memberikan interface yang hamper serupa dengan handphone, untuk melakukan fungsi-fungsi tersebut. Selain itu, SMS Gateway juga digunakan untuk melakukan otomatisasi pengelolaan sms, seperti mengirimkan sms ke banyak nomor tujuan, membalas sms secara otomatis dan sebagainya, tergantung aplikasi SMS Gateway itu dirancang. Dengan menggunakan SMS Gateway di SMK Taruna Persada Dumai sistem akan mengirimkan informasi absensi siswa kepada pihak orangtua jika siswa tersebut sengaja tidak hadir tanpa kabar, dan sistem juga akan memberitahukan nilai-nilai siswa yang diberikan oleh guru yang bersangkutan sehingga mencegah terjadinya penyelewengan nilai.

\section{a. Sistem}

Sistem adalah sebuah tatanan (keterpaduan) yang terdiri atas sejumlah komponen fungsional (dengan satuan fungsi/tugas khusus) yang saling berhubungan dan secara bersama-sama bertujuan untuk memenuhi suatu proses atau pekerjaan tertentu.

Jadi dapat disimpulkan diatas bahwa sistem merupakan suatu kumpulan dari subsistem-subsistem yang saling berhubungan untuk memenuhi suatu tujuan tertentu.(Rohayati \& HJ, 2016)

\section{b. Data}

Data adalah fakta yang belum bermakna sehingga perlu diolah agar dapat bermakna, yaitu informasi. Informasi ini akan diterima 


\section{INFORM T I K A}

Jurnal Informatika, Manajemen dan Komputer, Vol. 9 No. 2, Desember 2017

eISSN : 2580-3042

pISSN : 1979-0694

pengguna yang membuat keputusan yang menghasilkan tindakan sehingga dihasilkan data baru sehingga membentuk suatu siklus.

Jadi, data adalah fakta yang belum diolah agar mendapatkan makna dan berbertuk informasi yang penting, yaitu siklus pengolahan data sebagai berikut :

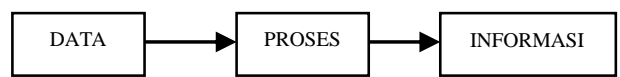

Gambar 1. Siklus Informasi

Sumber : (Ismael, 2017)

Berdasarkan tingkat kompleksitas nilai data, tingkatan data dapat disusun kedalam sebuah hirarki, mulai dari yang paling sederhana hingga yang paling komplek.

1. basis data, merupakan sekumpulan dari bermacam-macam tipe record yang memiliki hubungan antar record.

2. berkas/file, merupakan sekumpulan rekaman data yang berkaitan dengan suatu objek.

3. record, merupakan sekumpulan field/atribut/data item yang saling berhubungan terhadap obyek tertentu.

4. field/atribut/data item, merupakan unit terkecil yang disebut data, yang tidak dapat dipecah lagi menjadi unit lain yang bermakna.

5. byte, merupakan sekumpulan bit yang secara konvensional terdiri atas kombinasi delapan bit yang menyatakan sebuah karakter dalam memori (1 byte $=1$ karakter) .(Drs. Hermansyah Sembiring \& Nurhayati, S.Kom., 2012)

\section{c. SMS Gateway}

SMS Gateway adalah suatu aplikasi yang memungkinkan kita untuk menerima atau mengirim SMS, sebagai pengganti perangkat telekomunikasi (handphone, modem). Ketika kita menerima/mengirim SMS, maka kita akan memakai fungsi dan tombol yang ada pada handphone.

Aplikasi SMS Gateway memberikan interface yang hampir serupa dengan handphone, untuk melakukan fungsi-fungsi tersebut. Selain itu, SMS Gateway juga digunakan untuk melakukan otomasisasi pengelolaan SMS, seperti mengirimkan SMS ke banyak nomor tujuan, membalas SMS secara otomatis dan sebagainya, tergantung aplikasi SMS Gateway itu dirancang.

Jadi aplikasi SMS Gateway tidak sepenuhnya menggantikan fungsi perangkat

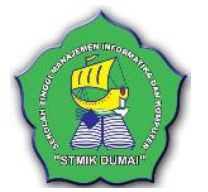

telekomunikasi handphone,modem). SMS Gateway masih membutuhkan hardware tersebut untuk berkomunikasi dengan jaringan provider telekomunikasi. SMS Gateway hanya menggantikan fungsi antar muka (interface) yang semula harus dilakukan langsung dari handphone / modem, kini bisa dilakukan dari SMS Gateway. Aplikasi SMS Gateway dibuat untuk menambah fungsi yang berhubungan dengan otomatisasi pengelolaan sms.(Basuki, 2017)

\section{d. Absensi}

Absensi dapat dikatakan sebagai suatu pendataan kehadiran yang merupakan bagian dari aktifitas pelaporan yang ada dalam sebuah institusi. Absensi disusun dan diatur sehingga mudah untuk dicari dan dipergunakan ketika diperlukan oleh pihak yang berkepentingan.

Secara umum jenis-jenis absensi menurut cara penggunaannya dapat dikelompokkan menjadi dua, yaitu:

1 Absensi Manual, yang merupakan cara penulisan kehadiran dengan cara menggunakan pena berupa tanda tangan.

2 Absensi non manual, yang merupakan cara penulisan kehadiran dengan menggunakan alat yang terkomputerisasi, bisa menggunakan kartu RIFD ataupun fingerprint.(Setiawan \& Kurniawan, 2015)

\section{e. Nilai}

Nilai dalam bahasa inggris disebut value berarti harga, penghargaan, atau tafsiran. Artinya, harga atau objek penghargaan yang melekat pada sebuah objek. Objek yang dimaksud adalah berbentuk benda, barang, keadaan, perbuatan, atau perilaku. Nilai adalah sesuatu yang abstrak, bukan konkret. Nilai hanya bisa dipikirkan, dipahami dan dihayati. Menilai berarti menimbang, yaitu kegiatan manusia yang menghubungkan sesuatu dan sesuatu yang lain untuk mengambil suatu keputusan.(Heri Prasetyo \& Arliando, 2015)

\section{f. Short Message Service Gateway}

SMS Gateway adalah suatu aplikasi yang memungkinkan kita untuk menerima atau mengirim SMS, sebagai pengganti perangkat telekomunikasi (handphone, modem). Ketika kita menerima/mengirim SMS, maka kita akan memakai fungsi dan tombol yang ada pada handphone. Aplikasi SMS Gateway memberikan interface yang hampir serupa dengan handphone, untuk melakukan fungsifungsi tersebut. Selain itu, SMS Gateway juga digunakan untuk melakukan otomasisasi 


\section{INFORM T I K}

Jurnal Informatika, Manajemen dan Komputer, Vol. 9 No. 2, Desember 2017

eISSN : 2580-3042

pISSN : 1979-0694

pengelolaan SMS, seperti mengirimkan SMS ke banyak nomor tujuan, membalas sms secara otomatis dan sebagainya, tergantung aplikasi SMS Gateway itu dirancang. Jadi aplikasi SMS Gateway tidak sepenuhnya menggantikan fungsi perangkat telekomunikasi (handphone, modem). SMS Gateway masih membutuhkan hardware tersebut untuk berkomunikasi dengan jaringan provider telekomunikasi. SMS Gateway hanya menggantikan fungsi antar muka (interface) yang semula harus dilakukan langsung dari handphone / modem, kini bisa dilakukan dari SMS Gateway. Aplikasi SMS Gateway dibuat untuk menambah fungsi yang berhubungan dengan otomatisasi pengelolaan sms. (Basuki, 2017)

\section{g. GAMMU}

Gammu adalah aplikasi open source, yang berfungsi sebagai antar muka yang menghubungkan handphone / modem dengan komputer. Sehingga kita bisa mengontrol hp / modem dari komputer. Aplikasi semacam inilah yang sebenarnya merupakan jantung dari aplikasi SMS Gateway.

Gammu sering dipilih sebagai platform utama untuk membangun aplikasi SMS Gateway karena mendukung banyak tipe perangkat keras telekomunikasi (handphonel modem) dari berbagai vendor / merek. (Basuki, 2017)

\section{a. $\mathbf{P H P}$}

PHP (Hypertext Preprocessor) merupakan bahasa pemograman yang berjalan dalam sebuah webserver dan berfungsi sebagai pengolahan data pada server. Dengan menggunakan program PHP, sebuah website akan lebih interaktif dan dinamis.(Madiun, 2011)

PHP merupakan bahasa pemrograman yang berbasis website server, PHP berbeda dengan bahasa pemrograman Java yang berbasis client service. PHP digunakan untuk membuat aplikasi website yang disusun oleh kode-kode (syntak) yang diatur berdasarkan algoritma program yang dibuat. Penggunaan PHP semakin luas untuk aplikasi-aplikasi website dalam berbagai keperluan bisnis, bahkan PHP telah banyak digunakan oleh para web master karena kemudahannya dan keefektifannya.(Saefudin, 2011)

\section{b. Notepad++}

Notepad++ merupakan sebuah aplikasi penyunting teks dan penyunting kode sumber yang berjalan disistem operasi windows.

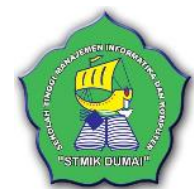

Notepad++ menggunakan komponen Scintilla untuk dapat menampilkan dan menyuntingkan teks dan berkas kode sumber berbagai bahasa pemograman. Notepad ++ didistribusikan sebagai perangkat lunak bebas. Proyek ini dilayani oleh Source.net yang telah diunduh lebih dari 27 juta kali dan dua kali memenangkan penghargaan Source Forge Comumunity Choice Award for Developer Tool. (Wahana Komputer, 2014)

\section{c. MYSQL}

MySQL merupakan Relational Database Management System (RDBMS), karena dapat mengatur data tentang bidang subyek yang berbeda ke dalam tabel-tabel. Pendekatan ini memudahkan membawa data yang terkait bila dibutuhkan. Dengan membentuk hubungan di antara tabel-tabel terpisah, bukannya menyimpan semua informasi dalam satu tabel besar, berarti dapat menghindari duplikasi banyak data, menghemat ruang penyimpanan dalam komputer dan memaksimalkan kecepatan dan akurasi kerja data. MySQL membantu mengelola database dengan cara menyediakan struktur efisien untuk menyimpan dan mengambil informasi.(Saefudin, 2011)

\section{d. SQL}

SQL (Structured Query Language) adalah bahasa non procedural untuk mengakses data pada database relasional. SQL adalah bahasa database yang dipergunakan dalam menyelesaikan permasalahan dalam database serta mempunyai kelebihan dalam mengolah data. Standar SQL mula-mula didefenisikan oleh ISO (International Standards Organization) dan ANSI (the American National Standards Institute) yang dikenal dengan sebutan SQL86.

Dengan menggunakan SQL, kita dapat melakukan hal-hal berikut:

1. Memodifikasi struktur database.

2. Mengubah, mengisi, menghapus isi database.

3. Mentransfer data antara database yang berbeda.(Siswandy, 2017)

\section{e. BOOSTRAP}

Bootstrap merupakan sebuah framework yang dapat menyelesaikan permasalahan dalam mendesain web. Slogan dari framework ini adalah "Sleek, intuitive, and powerful front-end framework for faster and easier web development", yang berarti kita dapat mendesain sebuah website dengan lebih rapi, cepat dan mudah. Selain itu Bootstrap juga 


\section{INFORMA TIK}

Jurnal Informatika, Manajemen dan Komputer, Vol. 9 No. 2, Desember 2017

eISSN : 2580-3042

pISSN : 1979-0694

responsive terhadap banyak platform, artinya tampilan halaman website yang menggunakan Bootstrap ini akan tampak tetap rapi, baik versi mobile maupun desktop. (Jurnal Nasional Informatika dan Teknologi Jaringan, 2016: 7 ).

Beberapa paket yang terdapat didalam framework bootstrap yaitu:

1. Scaffolding

Struktur Framework Bootstrap menyediakan struktur dasar dengan Grid System, link style dan background.

2. CSS (Cascading Style Sheets)

Framework Bootsrap menampilkan pengaturan CSS secara global, elemen dasar HTML ditata dan ditingkatkan dengan extensible class dan advanced grid system.

3. Components

Bootstrap memiliki banyak komponen yang dapat digunakan kembali seperti penggunaan navigasi, dropdowns, alert dan lain-lain.

4. Javascript plugins

Bootstrap juga memiliki banyak plugin jQuery yang dapat digunakan dan dapat dimodifikasi sesuaikan dengan kebutuhan.

5. Customize

Komponen-komponen yang terdapat Bootstrap dan plugin jQuery dapat dirubah atau dikembangkan kedalam versi terbarunya.(Zakir, 2016)

\section{f. XAMPP}

Xampp merupakan singkatan dari $\mathrm{X}$ (empat sistem operasi apapun), Apache, Mysql, PHP, dan Perl. Xampp adalah tool yang menyediakan paket perangkat lunak dalam satu buah paket. Dalam paket Xampp sudah terdapat Apache (web server), Mysql (database), PHP (server side scripting), Perl ,FTP server, PhpMyAdmin dan berbagai pustaka bantu lainya.

Versi XAMPP 1.8.1 (untuk Windows) yang terdiri atas aplikasi-aplikasi berikut:
a. Apache 2.4.3
b. MySQL 5.5.2.7
c. PHP 5.4.7
d. PhpMyAdmin 3.5.2.2
e. FileZilla FTP Server 0.9.4.1
f. Tomcat 7.0.30 (with mod_proxy_ajp as connector)
g. Strawberry Perl 5.16.1.1 Portable
h. XAMPP Control Panel 3.1.0 (from hackattack142). (Zakir, 2016)

\section{METODOLOGI PENELITIAN}

Adapun metodologi yang digunakan pada penelitian ini :

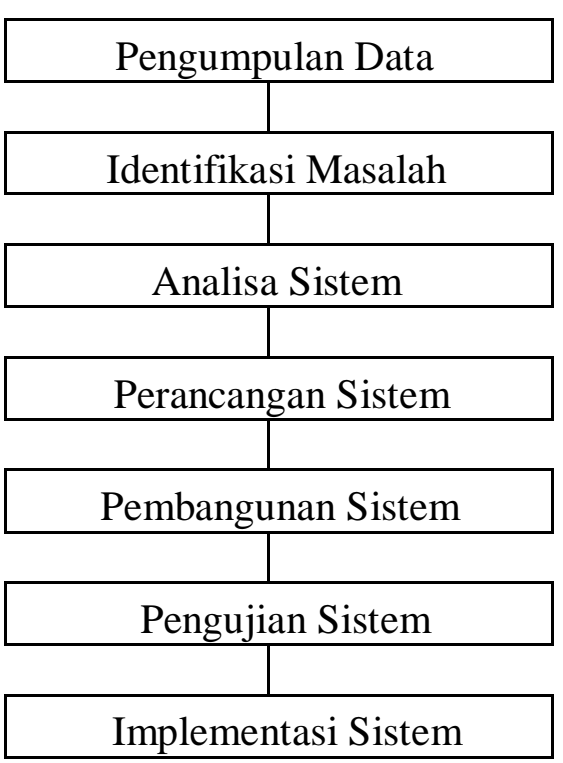

Gambar 2. Kerangka Kerja

Berikut ini penjelasan dari gambar Kerangka Kerja diatas:

1. Teknik Pengumpulan Data

Tahap pertama yang dilakukan adalah pengumpulan data dengan teknik Wawancara dan Observasi.

a. Teknik wawancara digunakan dalam pengumpulan data untuk mendapatkan jawaban pertanyaan dari pihak SMK Taruna Persada Dumai.

b. Observasi untuk pengumpulan data dengan mengadakan pengamatan terhadap sistem kerja dari permasalahan yang diteliti.

2. Identifikasi Masalah

Tahapan selanjutnya untuk membuat Aplikasi Layanan Informasi Absen dan Nilai ini adalah dengan mengetahui persoalan atau masalah- masalah apa yang sedang dihadapi dalam penelitian ini.

3. Analisa Sistem

Untuk membuat sebuah sistem lama atau sistem baru dibutuhkan analisa terhadap sistem yang akan di rancang dan dibuat, agar sistem yang akan dihasilkan nanti sesuai dengan tujuan dan hasil yang diharapkan.

4. Perancangan Sistem

Merancang sistem yang dibutuhkan dalam membangun Aplikasi layanan informasi Absen dan Nilai yaitu perancangan input, output yang sesuai dan memenuhi kebutuhan sistem.

5. Pembangunan Sistem 
INFORMA T IKA

Jurnal Informatika, Manajemen dan Komputer, Vol. 9 No. 2, Desember 2017

eISSN : 2580-3042

pISSN : 1979-0694

Pada tahap ini dilakukan pembangunan sistem dari perancangan sistem yang telah dilakukan sebelumya dengan menggunakan pemrograman PHP.

6. Pengujian Sistem

Tahapan selanjutnya adalah pengujian program dengan menjalankan program yang telah dirancang.

7. Implementasi Sistem

$\begin{array}{llr}\text { Pada tahap ini dilakukan } \\ \text { pengimplementasian } & \text { sistem } & \text { untuk }\end{array}$ pengimplementasian sistem untuk
mendapatkan hasil yang sesuai dengan yang diharapkan.

3. HASIL DAN PEMBAHASAN

a. Aliran Sitem Informasi Yang Sedang Berjalan.

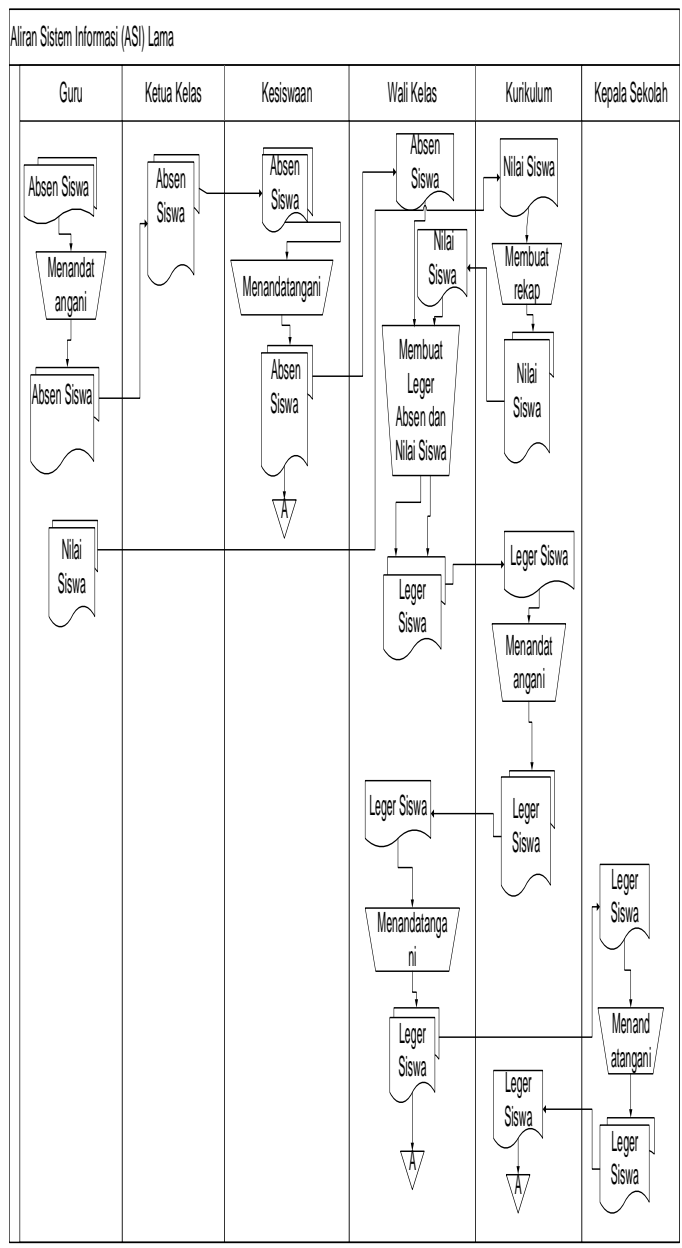

Gambar 3. Aliran Sistem Informasi

\section{b. Context Diagram}

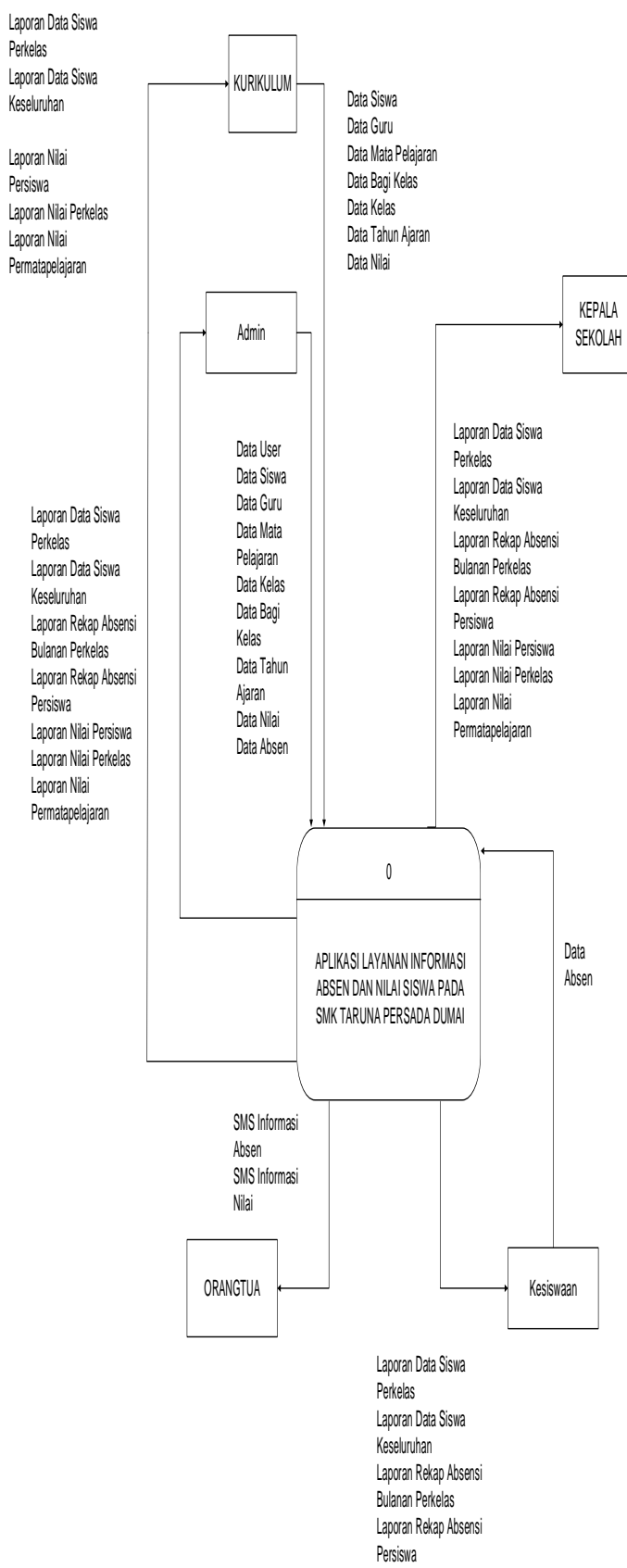

Gambar 4. Context Diagram 
I N F O R M A T I K A

Jurnal Informatika, Manajemen dan Komputer, Vol. 9 No. 2, Desember 2017

eISSN : 2580-3042

pISSN : 1979-0694

\section{c. Data Flow Diagram}

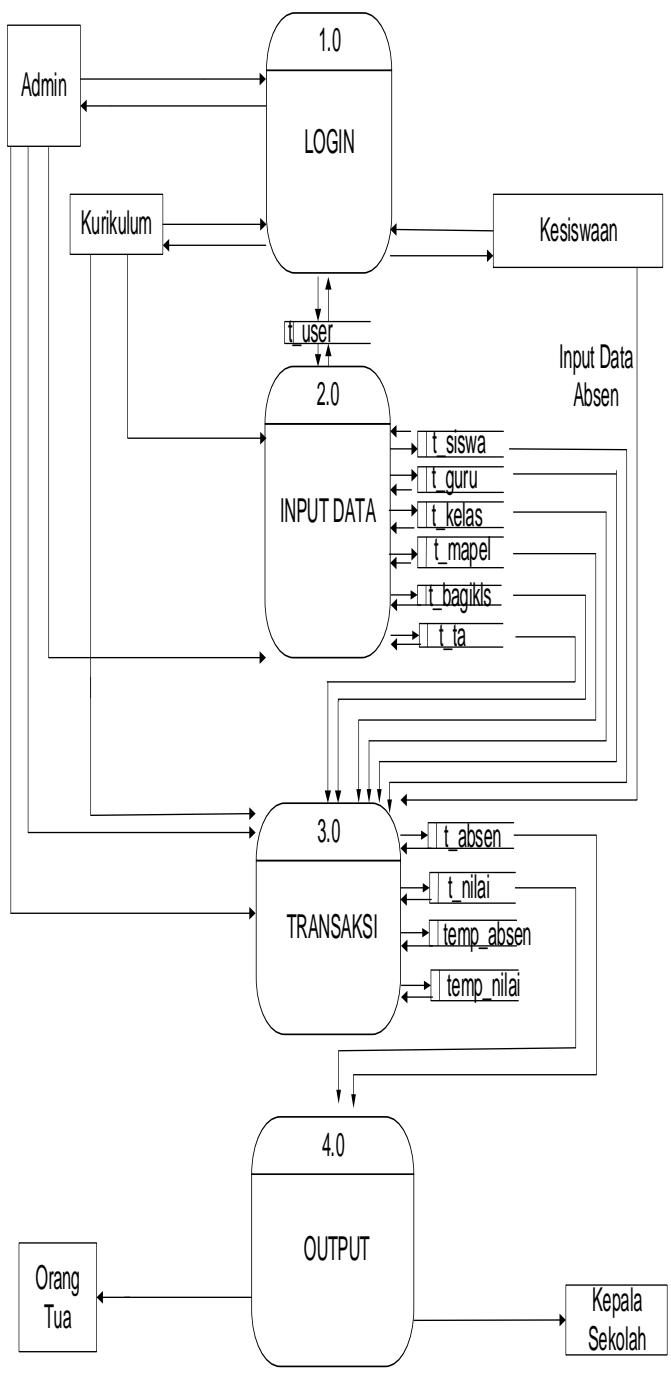

Menerima SMS Absen

dan SMS Nilai Siswa
Laporan Data Siswa Perkelas Laporan Data Siswa Keseluruhan Laporan Rekap Absensi Bulanan Perkelas Laporan Rekap Absensi Persiswa Laporan Nilai Persiswa Laporan Nilai Perkelas Laporan Nilai Permatapelajaran

Gambar 5. Data Flow Diagram

d. Entity Relationship Diagram

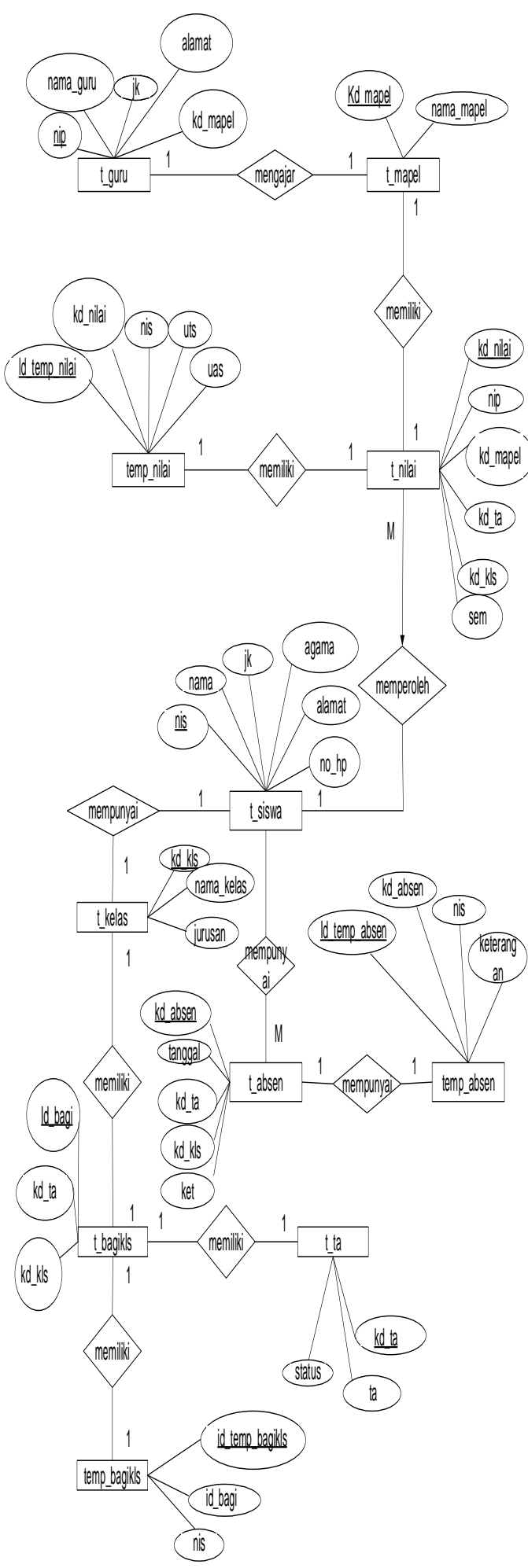

Gambar 6. Entity Relationsip Diagram 
INFORM T IKA

Jurnal Informatika, Manajemen dan Komputer, Vol. 9 No. 2, Desember 2017

eISSN : 2580-3042

pISSN : 1979-0694

\section{e. Tampilan Program}

Untuk membuka sistem masukkan username dan password yang sudah ada di database. Sistem ini memiliki 4 hak akses untuk admin, kurikulum, kesiswaan dan kepala sekolah. Admin dapat mengakses keseluruhan sistem. Kurikulum bertugas menginput data nilai sedangkan kesiswaan bertugas menginout data absen siswa. Sedangkan Kepala sekolah hanya melihat semua laporan pada sistem. Pada halaman login, jika username dan password benar maka sistem akan terbuka, jika username dan password salah maka akan kembali ke halaman login.

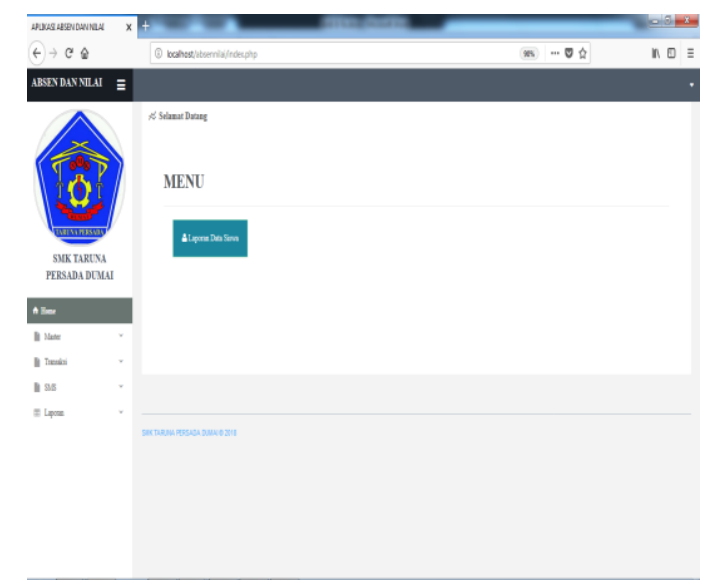

Gambar 7. Menu Admin

Pada form master terdapat tombol input data dan aksi, tambah data bagian dan aksi. Pada aksi terdapat perintah "edit" dan "hapus". "edit" untuk mengubah data yang telah dipilih, sedangkan "hapus" untuk menghapus data.

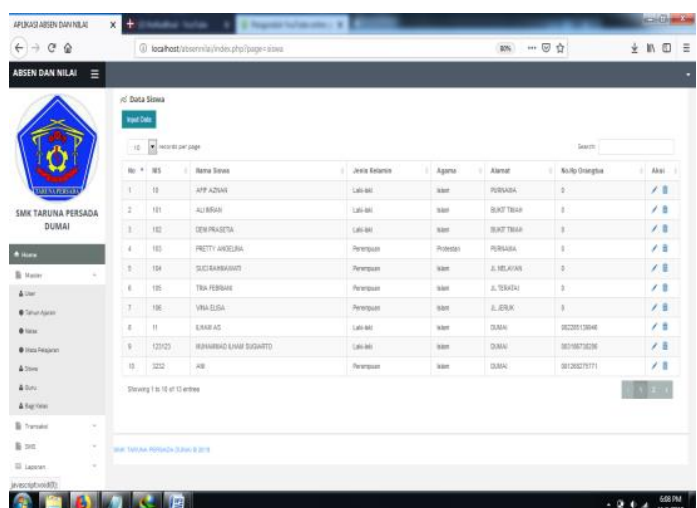

Gambar 8. Form Data Siswa

Pada halaman menu master pilih data siswa di menu master .Pada form data siswa terdapat Input data siswa. Input pembagian kelas adalah menginput siswa berdasarkan kelas-kelas yang ingin diinput.

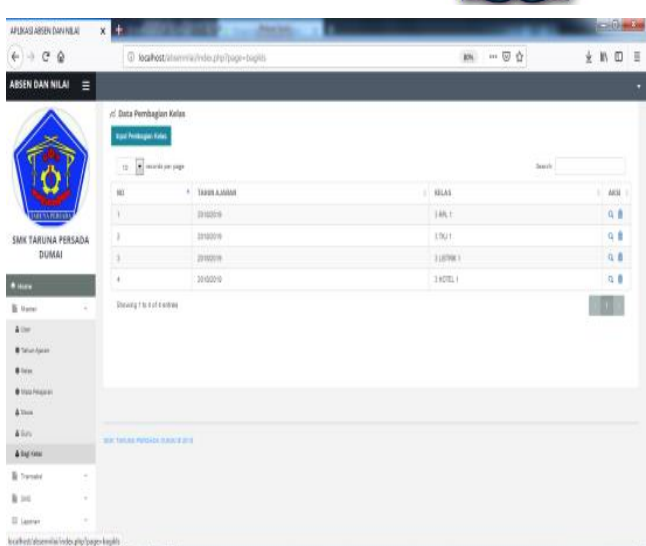

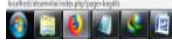

Gambar 9 Form Data Bagi Kelas

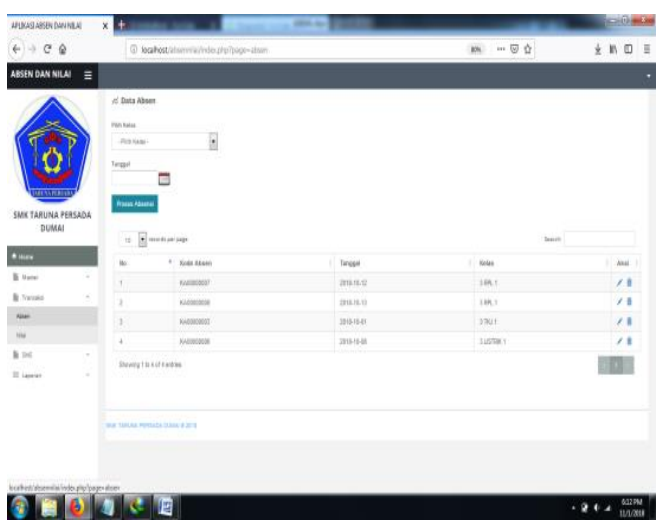

Gambar 10. Form Input Absen

Pada data absen terdapat form untuk menginput, menegdit dan memghapus data, setelah data absen diinputkan jika siswa tersebut alfa maka sistem otomatis mengirimkan sms kepada orangtua siswa melalui nomor hanphone yang telah terdaftar di sistem.

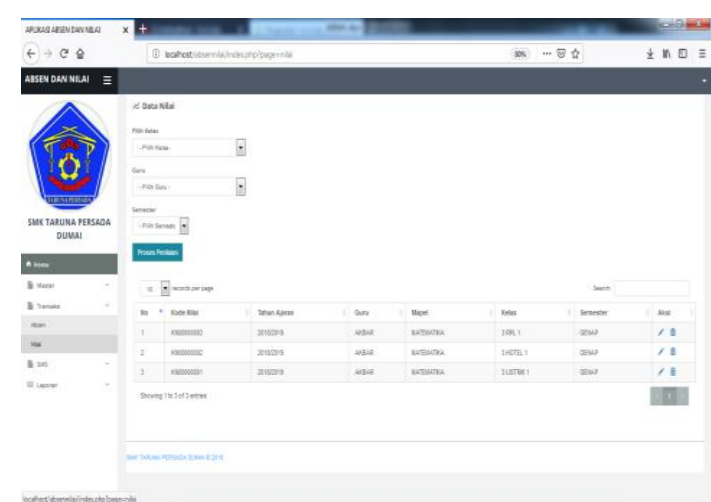

\section{Q日e}

Gambar 11. Form Data Nilai

Sedangkan untuk form nilai terdapat form untuk menginput data nilai, menghapaus, dan mengedit data nilai. Sistem akan otomatis mengirimkan nilai siswa jika nilai tersebut diinputkan. 
I N F ORM A T I R

Jurnal Informatika, Manajemen dan Komputer, Vol. 9 No. 2, Desember 2017

eISSN : 2580-3042

pISSN : 1979-0694

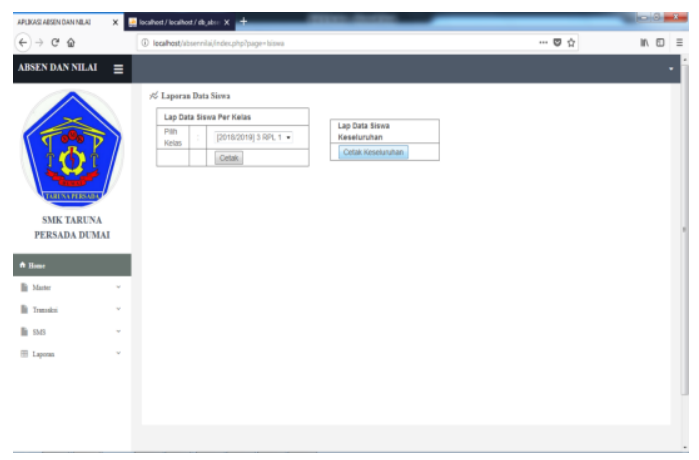

Gambar 12. Filter Data Laporan Data Siswa

Pada halaman menu utama pilih Laporan data siswa keseluruhan di menu Laporan. Pada laporan data siswa keseluruhan klik cetak kemudian akan tampil laporan data siswa keseluruhan.

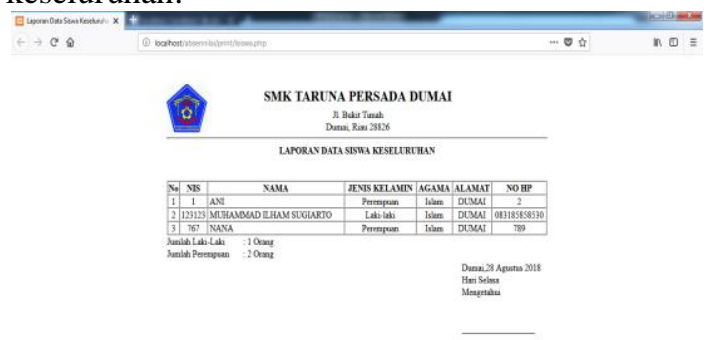

Gambar 13. Data Laporan Siswa Keseluruhan

Pada halaman menu utama pilih Laporan rekap absen bulanan perkelas di menu Laporan. Pada laporan rekap absen bulanan perkelas pilih kelas, pilih bulan dan tahun, klik cetak kemudian akan tampil laporan rekap absensi bulanan perkelas.

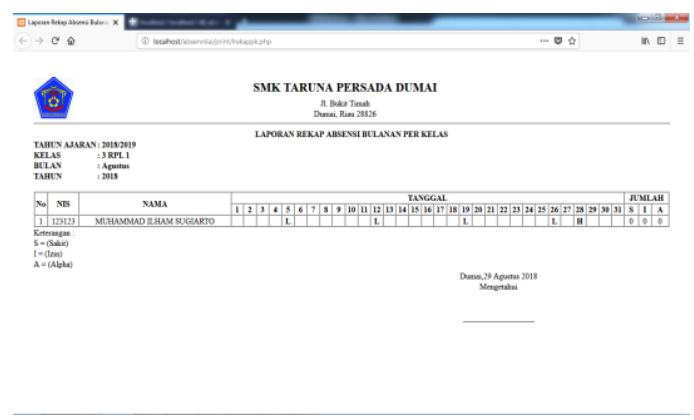

\section{Gambar 14. Laporan Data Rekap Absensi} Bulanan Perkelas

Pada halaman menu utama pilih Laporan rekap absensi persiswa di menu Laporan. Pada

form laporan absen terdapat laporan rekap absensi bulanan perkelas dan rekap absensi persiswa. Pada laporan rekap absensi persiswa pilih tahun ajaran dan kelas, pilih siswa, klik cetak kemudian akan tampil laporan.

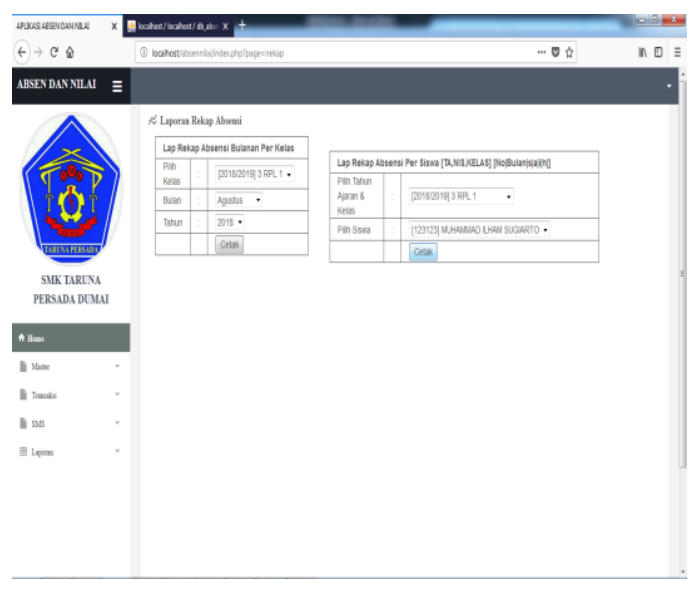

Gambar 15. Filter Data Laporan Rekap Absensi Persiswa

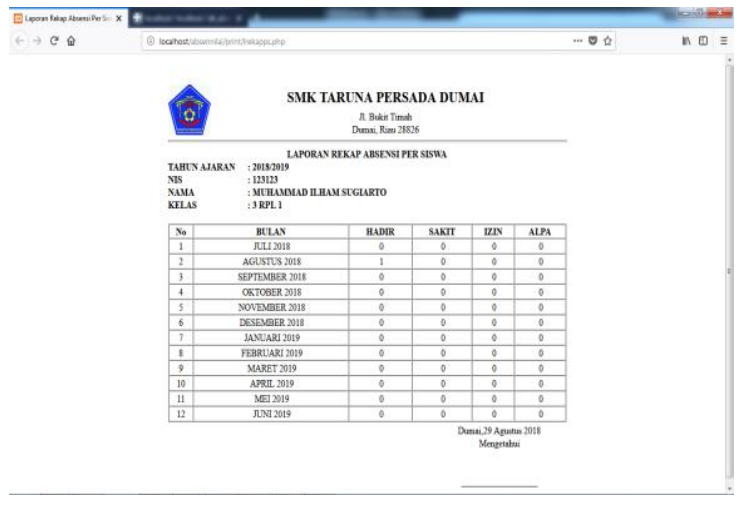

Gambar 16 Data Laporan Rekap Absensi Persiswa

Sedangkan untuk laporan absen persiswa terdapat laporan berdasarkan tahun ajaran, dimana terdapat keterangan izin, sakit, alfa dan hadir siswa.

Pada halaman menu utama pilih Laporan nilai persiswa di menu Laporan. Pada form laporan nilai terdapat laporan nilai persiswa, perkelas dan permapel. Pada laporan nilai persiswa input tahun ajaran, pilih semester dan pilih siswa, kemudian cetak maka tampil laporan data nilai persiswa. Pada laporan nilai perkelas input data tahun ajaran dan kelas kemudian input data semester. Sedangkan pada laporan nilai permatapelajaran input data tahun ajaran dan kelas, input semester, input 
IN F O R M A T I A

Jurnal Informatika, Manajemen dan Komputer, Vol. 9 No. 2, Desember 2017

eISSN : 2580-3042

pISSN : 1979-0694

matapelajaran kemudian cetak maka akan tampil laporan.

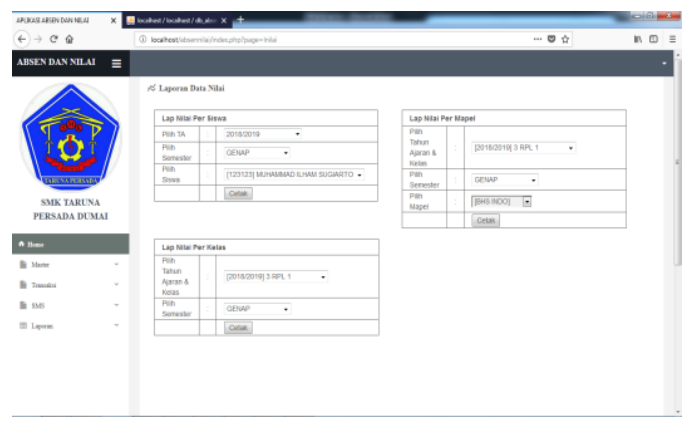

Gambar 17 Filter Data Laporan Nilai

Di menu filter data laporan nilai ini user bisa memilih laporan nilai yang diinginkan dengan menginput terlebih dahulu sesuai data yang ada di dalam database sistem ini.

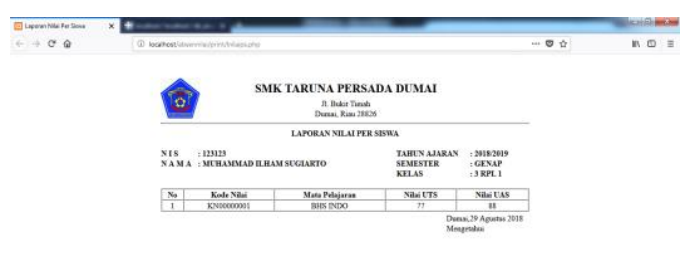

Gambar 18 Data Laporan Nilai Persiswa

Sedangkan didalam Laporan Nilai Persiswa terdapat field-field yang meliputi kode nilai untuk kode nilai yang diinput, nama matapelajaran untuk nama matapelajaran yang diinput didalam tabel form nilai, nsedangkan nilai uts, dan nilai uas berisi nilai siswa yang dimasukkan oleh user. Semua data laporan ini hasil inputan dari form nilai didalam transaksi sistem.

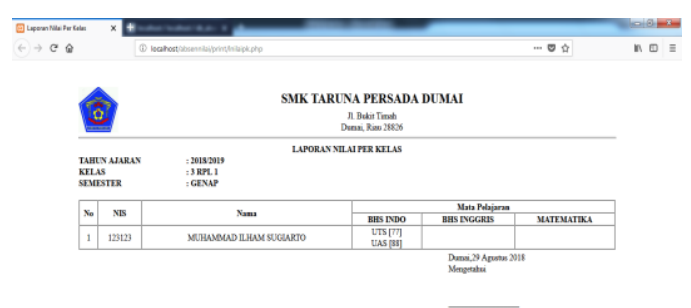

Gambar 19 Filter Laporan Nilai Perkelas

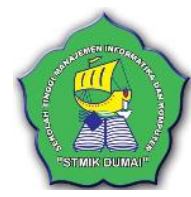

Sedangkan didalam Laporan Nilai Perkelas terdapat field-field yang meliputi nis, nama siswa, dan matapelajaran yang telah diinput didalam transaksi nilai.

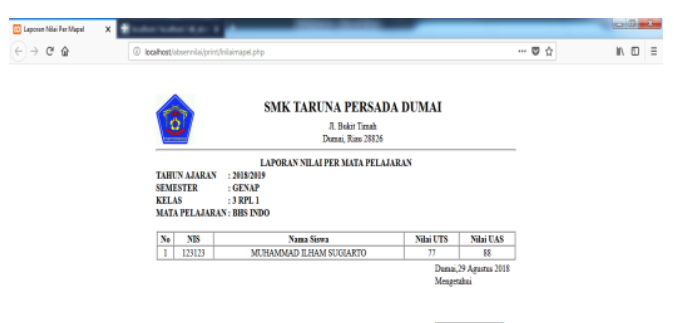

Gambar 20 Laporan Data Nilai Permatapelajaran

Langkah selanjutnya setelah menginput data Absen dan Nilai selanjutnya membuka laporan absensi bulanan perkelas kemudian pilih cetak untuk memuat laporan proses pencetakan, pastikan printer terhubung dengan komputer, disini laporan yang ditampilkan laporan absen bulanan perkelas dan nilai permata pelajaran.

\section{KESIMPULAN}

Aplikasi layanan informasi absen dan nilai berbasis sms gateway ini memilki tujuan agar bisa menjadi fasilitas penunjang dalam memberikan informasi tentang absen dan nilai siswa yang bisa diakses dengan sms, berdasarkan hasil penelitian maka dapat diambil kesimpulan antara lain:

1. Sistem ini memanfaatkan SMS gateway sebagai pemberithuan informasi absensi dan nilai siswa.

2. SMS yang masuk ke handphone orang tua/wali siswa dikirim secara otomatis saat melakukan transaksi absensi dan nilai, SMS absen terkirim jika siswa tersebut berstatus alfa sedangkan SMS nilai terkirim setiap menginput nilai.

3. Orangtua siswa dapat menerima pemberitahuan SMS melalui handphone jenis apapun yang mampu mengirim dan menerima Short Message Service (SMS) dari handphone tersebut.

\section{REFERENSI}

Basuki, A. (2017). Membangun Aplikasi SMS Gateway Berbasis Web dengan Codeigniter dan Bootstrap. 
I N F ORM A T I R

Jurnal Informatika, Manajemen dan Komputer, Vol. 9 No. 2, Desember 2017

eISSN : 2580-3042

pISSN : 1979-0694

Drs. Hermansyah Sembiring, M. K., \& Nurhayati, S.Kom., M. K. (2012). Sistem Informasi Jumlah Angkatan Kerja Menggunakan Visual Basic Pada Badan Pusat Statistik (Bps) Kabupaten Langkat. Jurnal KAPUTAMA， 5(2), 13-19. Retrieved from http://penelitian.kaputama.ac.id/images/sa mpledata/File/Jurnal/Jurnal2012/JURNAL 7.pdf

Heri Prasetyo, M., \& Arliando, Y. (2015). Sistem Informasi Nilai Mahasiswa Berbasis Sms Gateway Pada Fakultas Pertanian Universitas Bengkulu. Jurnal Media Infotama Sistem Informasi Nilai... ISSN, 11(1), 1858-2680.

Ismael. (2017). Jurnal EdikInformatika Semen Padang Untuk Daerah Bengkulu Selatan Di Jurnal EdikInformatika. Jurnal EdikInformatika, 2(2), 147-156.

Madiun, M. (2011). Aplikasi Web Database dengan Dreamweaver dan PHP-MySQL.

Rohayati, \& HJ, A. I. (2016). Perancangan dan implementasi sistem informasi inventaris laboratorium. Jurnal INTEKNA, 16(2), 15-19.

Saefudin, M. (2011). Aplikasi ticketing helpdesk kantor dengan php dan mysql. Jurnal Ilmiah “Komputasi," 10(1), 1-10.

Setiawan, E. B., \& Kurniawan, B. (2015). Perancangan Sistem Absensi Kehadiran Perkuliahan dengan Menggunakan Radio Frequency Identification ( RFId ). CoreIT, Vol.1,No.2, Desember 2015, 1(2), 44-49. https://doi.org/10.1186/17563305-3-27

Wahana Komputer. (2014). Mudah Membuat Aplikasi SMS Gateway dengan Codeigniter.

Zakir, A. (2016). Rancang Bangun Responsive Web Layout Dengan Menggunakan Bootstrap Framework. InfoTekJar (Jurnal Nasional Informatika Dan Teknologi Jaringan), 1(ISSN : 2540-7600), 7-10. https://doi.org/10.30743/infotekjar.v1i1.3 1 